\title{
Research on SNS and education: The state of the art and its challenges
}

\author{
Carlos Rodríguez-Hoyos, Ignacio Haya Salmón, Elia Fernández-Díaz \\ University of Cantabria
}

\begin{abstract}
This paper presents, for further discussion, a review of the scientific literature produced internationally on the use of Social Network Sites (SNS) in different levels of education and settings. A total of 62 articles published in international scientific journals with peer review have been analysed. The main objective of this paper is to discuss the most recurrent lines of research since the emergence of these tools in education. The level of education in which research is carried out is also analysed, as well as the paradigms and methods used for data collection. The analysis leads to the conclusion that most of the studies analysed have been carried out in higher education, from a quantitative paradigm, focusing on the use of SNS as educational tools. This article shows that research into SNS in education is at an early stage of development, and it demonstrates the need to widen lines of research on SNS in media education to include as yet unexplored dimensions.
\end{abstract}

\section{Introduction}

The emergence of Web 2.0 has created many expectations of change and transformation in different contexts and has led to the appearance of a great number of technological developments which have facilitated social interaction among users. One of these developments which has had a major impact on the daily reality of Internet users are Social Network Sites (SNS). Boyd and Ellison (2007) have defined these tools as spaces that allow users to create both public and semi-public profiles, compile lists that collect the profiles of other users and view connections made by users within the system. Adamic and Adar (2005) point out that SNS gather information on users' contacts in order to establish an interconnected social network, revealing how they connect with other users within the network and enabling the expansion of their social circle. Kim, Jeong and Lee (2010) understand SNS to be sites that enable internet users to be in contact with other people and build online communities.

SNS have undergone tremendous growth since their introduction. Some studies show the importance of social networks in the daily lives of internet users. The report by Nielsen (2012) shows that $20 \%$ of the time users are connected to the internet via personal computer is dedicated to managing social networks. This percentage increases to $30 \%$ when the connection is via mobile telephone. This study also shows that Facebook remains the most popular social network followed by Blogger and Twitter.

Although the emergence of social networks is a recent phenomenon, the impact they have had on different fields (marketing, politics etc.) has generated massive interest among the academics. Something similar has occurred in education, where the emergence of social networks has generated abundant research which has attempted to look into the possible educational uses of these spaces.

A thorough literature review of this field has been carried out, and some research trends generated on the educational use of tools such as Facebook or Twitter have been identified. Aydin (2012) conducted a review of research analysing the potential of Facebook as a learning environment but did not specify the number of research projects reviewed or the methodology followed. He outlined the main lines of research conducted so far on the subject: the profile of users of this social network, reasons for use, possible adverse effects, the use of Facebook as an educational environment, its effects on culture, language and education and the relation between Facebook and other personal variables. Manca and Ranierit (2013) reviewed scientific literature to identify and discuss the educational uses of Facebook and analyse if its pedagogic potential was being put into practice. In their review of 23 articles they identified that the main interest of researchers had been directed towards three major themes: analysing the instructional effectiveness of Facebook, identifying opportunities for the use of Facebook as a support and interactive tool for the purpose of learning and assessing the reaction of students to the use of Facebook as a learning tool. Gao, Luo and Zhang (2012) reviewed research generated on the use of microblogging in education, particularly using a social network like Twitter. In the 21 articles reviewed, the authors 
identified some recurrent themes like their use to facilitate formal learning activities and to support a more digitalised, flexible and free way of learning, such as the expansion of opportunities for spontaneous learning beyond the classroom or the formation of virtual learning communities.

The existence of these partial reviews suggested the need to carry out a more comprehensive study. This would allow a critical analysis of the literature produced so far, with the aim of reflecting on some of the epistemological decisions (objects of study, methodologies used etc.) academics have adopted when analysing the educational use of SNS.

\section{Main objective and research questions}

The primary objective of this study is to demonstrate and discuss the main results obtained by carrying out a critical review of the literature produced internationally on research that analyses the educational use of social networks. This study does not intend to come up with recommendations on the use of social networks in different educational settings, instead it is oriented at looking into the strategies and topics analysed so far by the academic community. The study will identify, amongst other questions, the main lines of research, in order to suggest new topics that are not being addressed or that are being addressed as minority issues. This study is a meta-research into those documents that have empirically analysed the use of social networks in education. This paper aims to answer the following research questions:

1) In which levels of education is research into social networks being carried out?

2) From which research paradigm are they being addressed and what are the most used data collection methods?

3) What lines of research are currently being developed and what are the main results of these studies?

\section{Research methods}

From a methodological point of view, a number of decisions were taken. This study, used a qualitative paradigm, introducing quantitative data to statistically estimate the combined result of individual works (Bearman, Smith, Carbone, Slade, Baik, Hughes-Warrnington \& Neumann, 2012). The approach is related to the definition of the research questions which, on one hand, are directed at describing how some of the variables relate to the use of SNS in educational processes, and on the other hand, at understanding how the academic research is approaching this subject matter.

The process began with the definition of research questions and the framework to be used, which enabled the definition of both the necessary search strategies and the protocols for summarising the content of the selected papers (Thomas \& Pring, 2004). At the same time, among the criteria used for the inclusion and exclusion of studies, account details such as the year of publication, the language, the academic profile of the journals or the peer review procedure used (Evans \& Benefield, 2001), were taken into accounts. These aspects will now be described in further detail.

Firstly, in order to obtain a panoramic picture of this field of study it was necessary not to limit the search to a particular social network. This decision allowed for a broader view of this field of knowledge which until now has been offered by other studies (Aydin, 2012; Gao et al., 2012; Manca \& Ranierit, 2013). Secondly, it was considered necessary to analyse only those studies whose quality had been assured through a process of peer review. Only empirical research published in scientific journals subject to peer review were selected, ruling out other contributions based on classroom experience or personal opinion. The study excluded contributions made by researchers at conferences and scientific meetings that have not been subsequently published in scientific journals with peer review process. Thirdly, the language used to carry out the search for studies to be analysed was English. Fourth, in order to carry out the initial search of research material, two of the most relevant general data bases in the field of social sciences (Web of Knowledge and Scopus) and one specifically on educational resources (ERIC, Education Resources Information Center) were used. The initial search of the databases allowed identification of the title of articles published in different scientific journals. The key words used for finding these studies were "social network and education", "social networking and education", "Facebook and education" and "Twitter and education". Finally, a time limit was established to include those papers published between 2008 and 2013. 
In order to carry out the final selection of articles several stages were developed. In the first, an initial selection of articles was made, ruling out those which did not meet all the criteria outlined earlier. As a result of this process the research team identified an initial sample of articles to be analysed. In the second stage, the articles selected were analysed using a coding table in which aspects such as the paradigm of research, the data collection methods, the level of education or the main results obtained were categorised. Some of the articles that had been initially selected were discarded because they were related with other fields of knowledge (computing engineering, marketing, etc.). In the third stage, the articles were independently analysed by each member of research team, developing a themed coding system that reflected the research trends of this study. In order to create the categories an inductive process from the content analysis of the selected articles was followed. The final coding system, which will be discussed further later on, was developed by consensus on the defined systems by each member of the team. It should be noted that following an initial analysis of the title and abstract of the selected papers, all content of these was thoroughly reviewed as will become clear in the section presenting the results. As a result, each paper was reviewed by three researchers, incorporating the information on each of the variables analysed in a grid of analysis which was then later discussed and compared in order to carry out a process of triangulation between experts (Johnson \& Turner, 2003).

\section{Results}

Following the final selection of articles, once those which did not meet the established criteria had been ruled out, 62 published articles were left to be analysed. While in the results of each category, some references are only mentioned by way of example in order to facilitate the reading process, references to all the articles analysed to produce this research appear in the bibliography.

\section{Educational level in which research is carried out}

One of the research questions led to the analysis of which groups are participating in the research being carried out on this medium in educational contexts. The results show that $87 \%$ of the studies analysed focus on higher education, $8 \%$ on secondary education and $2 \%$ on continuous training. In $3 \%$ of the studies analysed the level of education was not specified.

Table 1

Summary of the level of education in which research is conducted

\begin{tabular}{lcc}
\hline Categories & No. of studies & Percentage \\
\hline Higher Education & 54 & $87 \%$ \\
\hline Secondary & 5 & $8 \%$ \\
\hline Not specified & 2 & $3 \%$ \\
\hline Continuous Training & 1 & $2 \%$ \\
\hline
\end{tabular}

The education sector in which the largest number of studies was identified is at university level (Blair, 2013; McCarthy, 2013; Roblyer, McDaniel, Webb, Herman \& Witty., 2010; Sezen, 2012; Staines \& Lauchs, 2013; Tiryakioglu \& Erzurum, 2011; Veletsianos \& Kimmons; 2013), although other studies were found to have been carried out at other levels of education such as secondary albeit in a minority (Doerr-Stevens, Beach \& Boeser, 2011; Fardoun, Romero, Alghazzawi \& Ramírez, 2012), as well as in other educational settings such as training courses (Ranieri, Manca \& Fini, 2012). Other studies did not specify the level of education (Cheung, Chiu \& Lee, 2011).

The first interpretation that can be made is that the academic community is focusing its interests on higher education. This interest may be down to the fact that SNS sites have defined a minimum age for creating profiles in these spaces. Some studies show that this limitation is not taken into account by teenagers given that they create profiles at an early age (Ólafsson, Livingstone \& Haddon, 2013) and that SNS directed specifically at the creating of virtual educational communities exist which can be used at different levels such as primary or secondary (for example, Edmodo).

The research conducted demonstrates that the main concern of the academics in all levels of education has been, until now, to analyse what the main results of the integration processes of SNS are in higher 
education teaching (Junco, Elavsky, \& Heiberger, 2013; Lam, 2012), secondary education (Doerr-Stevens et al., 2011; Fardoun et al., 2012) or in teacher training (Ranieri et al., 2012). This common interest appears to be related to the fact that it is a recent type of technological development which has spread very rapidly among the population, something which has prompted the academic community to seek to examine from different subject areas in the different variables of the use of SNS.

\section{Research Paradigms and methods used for data collection}

With regard to research methodology and the methods used for data collection, it should be noted that $42 \%$ of the studies analysed were conceived from a quantitative paradigm, compared to $32 \%$ of those which were established from a qualitative perspective and $26 \%$ which combined strategies from both paradigms.

Table 2

Research paradigms identified

\begin{tabular}{lcc}
\hline Categories & No. of studies & Percentage \\
\hline Quantitative & 26 & $42 \%$ \\
\hline Qualitative & 20 & $32 \%$ \\
\hline Mixed & 16 & $26 \%$ \\
\hline
\end{tabular}

The first interpretation of this data is that the quantitative paradigm has been the most used when designing research into SNS (Junco, 2012; Madge, Meek, Wellens \& Hooley, 2009; Roblyer et al., 2010). Within this category the most popular data collection technique was the use of questionnaires. This method has been used in different levels of education with the main aim of finding out the level of satisfaction of students participating in processes using SNS (Falahah \& Rosmala, 2012; Park, Cha, Lim \& Jung., 2013; Wang, Woo, Lang, Yang \% Liu, 2011), describing the educational potential that users identified in the tools included in these technological developments (Kamarul, Ahmad \& Jafre, 2010; Tiryakioglu, \& Erzurum, 2011) or types of uses outside an educational context (Ahn, 2011; Bicen, \& Cavus, 2012; Cam \& Isbulan, 2012). Within this paradigm a study which used statistics generated by SNS to measure the type of use by users was identified (Lim \& Ismail, 2010). These are all studies designed from descriptive statistics. In the studies analysed, within a quantitative paradigm, the size of the sample is variable. Thus there are studies whose samples range from between 50 and 90 participants (Brady, Holcomb, \& Smith, 2010; Lowe \& Laffey, 2011; Tiryakioglu, \& Erzurum, 2011), and other studies with over 100 participants (Rinaldo, Tapp \& Laverie, 2011).

The second most used paradigm for the analysis of the educational uses of SNS has been qualitative. Studies were identified, in which compared to the more descriptive nature of quantitative studies, an attempts have been made have to understand what the development process of educational experience. These include the use of SNS (e.g., Blair, 2013; Kawka, Larkin, \& Danaher, 2012; Rambe, 2012; Reich, Levinson \& Johnston, 2011) or how students at different levels of education use SNS in their daily lives (e.g., Bosch, 2009; Selwyn, 2009). The content of the different types of interaction produced by participants in virtual spaces needs to be analysed. Within this paradigm other sources of methodological inspiration such as case studies on a variety of learning experiences have been frequently used (e.g., Arnold \& Paulus; 2010; Çoklar, 2012; Dunlap \& Lowenthal, 2009). These studies inspire a hermeneuticinterpretive epistemological position aimed at understanding what happens in the teaching-learning process when using SNS.

Those studies in which research is designed combining methodologies that are traditionally categorised in the paradigms described earlier also have a significant presence. The majority of the studies based on this approach try to triangulate information from different sources using questionnaires combined with other methods such as interviews (Jones, Backey, Fitzgibbon \& Chew,2010; Lowe \& Laffey, 2011) or focus groups (Rinaldo et al., 2011; Yan Yu, Wen, Vogel \& Chi-Wai, 2010). Some studies directed at analysing the process of using of different SNS have been identified, in which a qualitative or quantitative analysis is carried out of the content generated in SNS complete with data obtained by using other methods such as interviews, focus groups, etc. (Fewkes \& McCabe, 2012; Knight \& Rochon, 2012; McCarthy, 2012;). Within this mixed research paradigm some experimental or quasi-experimental studies have been developed aimed at analysing to what extent the use of a certain SNS affects the results obtained by 
students by comparing a control group and an experimental one (Junco, Elavsky \& Heibergert, 2013; Junco, Heiberger \& Loken, 2011).

\section{Lines of research interests and main results}

From the analysis, the main lines of research with regards to the study of SNS from an educational perspective have been traced. The largest category was the use of SNS as an educational tool (71\% of the studies identified), followed by student use (19\%), institutional use (5\%), academic use (3\%) and design of SNS (2\%).

Table 3

Lines of research identified

\begin{tabular}{lcc}
\hline \multirow{2}{*}{ Categories } & No. of studies & Percentage \\
\cline { 2 - 3 } Uses of SNS as educational & 28 & $45 \%$ \\
\cline { 2 - 3 } tools & 8 & $13 \%$ \\
\cline { 2 - 3 } & 5 & $8 \%$ \\
\hline Other uses of SNS by students & 12 & $5 \%$ \\
\hline Institutional Uses & 3 & $19 \%$ \\
\hline Academic Uses & 2 & $5 \%$ \\
\hline Design of SNS & 1 & $3 \%$ \\
\hline
\end{tabular}

Use of SNS as educational tools

The largest category consists of research that, generically, has focused on analysing the potential of SNS as educational tools. Within this category four subcategories were identified, which will now be explained.

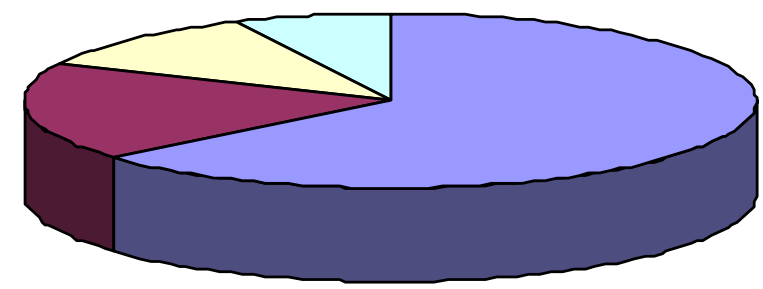

$\square$ Use of SNS on teachinglearning

$\square$ Social relations

$\square$ Educational potencial

$\square$ Ethical implications

Figure 1. Subcategories of use of SNS as educational tools

The largest subcategory is the one that consists of studies that analyse how the use of SNS has affected different variables related to the development of teaching-learning processes (Blair, 2013; Brady et al., 2010; English \& Duncah-Howell, 2008; Pimmer, Linxen \& Gröhbiel, 2012; Sezen, 2012). In most of the studies reviewed some positive aspects of the transformation of a social tool into an educational one, like in the case of SNS, have been identified. Some research demonstrates the positive influence that these tools can have on the development of online academic discussions (English \& Duncah-Howell, 2008; Lim \& Ismail, 2010; Pimmer et al., 2012; Wang et al., 2011), on the processes of reflection on educational content (Brady et al., 2010), on increasing participation (Junco et al., 2011), on the efficiency of conveying teacher information (Falahah \& Rosmala, 2012), on the democratisation of learning processes (Blair, 2013), on the development of narrative fiction (Kawka et al., 2012) or on the motivation to learn (Lam, 2012; Sezen, 2012). 
In contrast, other studies have made it clear that the use of SNS may have some limitations or difficulties. Dilek, Karademirb and Cicek (2011) identify some factors that need to be taken into account in order to avoid confusing the student in processes where SNS are used such as design, headings or overstimulation, etc. Some studies have suggested that the use of SNS does not guarantee the participation of the student in these types of sites when they are used for educational purposes (Knight \& Rochon, 2012; Lowe \& Laffey, 2011; Reich et al., 2011). Low participation in SNS could be linked to its use as a tool for information rather than for discussion or collaboration between students (Fewkes \& McCabe, 2012), with their preferences for face to face interaction (Arnold \& Paulus, 2010) or the negative view that students have about the use of SNS in teaching-learning processes (Rinaldo et al., 2011).

The second subcategory consists of research that analyses up to what point SNS transform social relations when they are used in educational contexts (Dunlap \& Lowenthal, 2009; Hung \& Chi-Yin, 2010; Lampe, Wohn, Vitak, Ellison \& Wash, 2011; McCarthy, 2012; Park et al., 2013; Schroeder \& Greenbowe, 2009; Wang, 2012; Yan Yu et al., 2010). Some studies show the positive influence that these tools can have on student socialisation processes (Yan Yu et al. 2010), on the establishment of emotional links and on the consolidation of educational communities (Hung \& Chi-Yin, 2010; Park et al., 2013), on the monitoring of e-mentoring programmes developed internationally (McCarthy, 2012) or on the development of collaborative projects implemented among groups from different cultural backgrounds (Wang, 2012).

Another subcategory consists of exploratory research into opinions in which different educational agents, teachers or students, discuss the key benefits, potential, attitudes, etc arising from the conversion of SNS into educational tools (Çoklar, 2012; Güzin \& Koçak, 2010; Kamarul et al., 2010; Roblyer et al., 2010; Tiryakioglu \& Erzurum, 2011;). Among the main advantages that students identified with SNS is their ability to encourage motivation in some specific subjects such as English (Kamarul et al., 2010), the opportunities for exchanging information and interaction with other educational agents (Çoklar, 2012), their usability and the development of social relations (Güzin \& Koçak, 2010). Meanwhile Tiryakioglu and Erzurum (2011) demonstrated that the most suggested educational uses of Facebook by teachers, was as much the placing of advertisements as the distribution of work, while Roblyer et al. (2010) showed that the attitudes of students are more positive when integrating these technologies than those of teachers who prefer to use email.

The last subcategory consists of those studies which analyse some of the ethical implications arising from the use of SNS as educational sites. Some groups of students suggested that the use of SNS should only be linked to the development of leisure activities, not academic ones (Jones et al., 2010). The results of the study carried out by Baran (2010) show that one of the main problems that students identified with the use of SNS in educational contexts is the fact that they have to share some personal information with teaching staff. Foulger, Ewbank, Kay, Popp and Carter (2009) analysed some of the ethical questions relating to teacher involvement in social networks and concluded that if a lot of teachers use these types of tools it will be necessary to implement training processes on the ethical use of personal information shared on these sites.

Uses of SNS by students

The number of studies identified within this analytical category shows the importance the academic community has attached to this subject, converting it into the second most numerous category. It includes all studies which analyse the reasons for use and types of uses of SNS by students.

Two major tendencies were found within this category. On the one hand, some articles attempt to find out what types of uses and motivations lead students to use SNS outside an educational context (e.g., Ahn, 2011; Bicen \& Cavus, 2011, 2012; Cheung et al. 2011; Cam \& Isbulan, 2012; Davies, 2012; Pempek, Yermolayeva \& Calvert, 2009;). On the other hand a number of studies have researched the participation and socialisation of students in networks created in environments like, for example, the university (e.g., Bosch, 2009; Madge et al., 2009; Junco, 2012; Selwyn, 2009). These types of studies attempt to link variables related to more personal and informal uses with the relationships students establish through SNS in educational settings.

Other studies have analysed both the types of use as well as the motivation of students when using SNS in their personal lives. These studies have demonstrated that this group uses them mainly for social purposes 
(e.g., Cheung et al., 2011; Davies, 2012; Pempek et al., 2009) or for recreational use (e.g., Bicen \& Cavus, 2012). The usage data demonstrates the wide use of SNS by students. The studies reveal that $40 \%$ of university students participating in the study used Twitter more than 4 hours a day (Bicen \& Cavus, 2012). Some studies looked into the implications of different variables (ethnicity, gender or social class) in the use of SNS. Cam and Isbulan (2012) show that male university students use SNS more than female students and also that students from top courses used SNS more than those from less advanced courses. Ahn (2011) analysed the extent to which the digital divide exists in the use of SNS by North American teenagers. The study showed that teenage boys used SNS less than teenage girls and that older teenagers used them more than the younger ones. This study is important evidence which shows how the digital divide decreases. However, the study shows that socioeconomic indicators, such as parents' level of education, do not help predict the participation of teenagers in SNS.

\section{Institutional uses of SNS}

This category includes all those articles which look at how diverse educational institutions have been using SNS as a tool of communication. These studies suggest that so far, the integration of SNS in schools has not been developed efficiently and that they are used more as diaries rather than a way of interacting (Forkosh-Barucha \& Hershkovitz, 2012) and that there does not appear to be a clear strategy for their integration within institutional means of communication (Dabner, 2012). One of the main uses by institutions is recruiting students, promoting events or facilities as well as providing other information related to academic activity (Osborn \& LoFrisco, 2012).

\section{Uses of SNS by academics}

Another of the categories identified is related to the analysis of the types of activities that academics carry out using SNS. More specifically these studies address some of the possible tensions that can arise when trying to establish a balance between the personal and professional world when teachers try to use these tools. The study by Veletsianos and Kimmons (2013) highlighted the desire of teachers to use SNS in their daily lives without this having a negative impact on their work. Mazer, Murphy \& Simonds (2009) suggest that academics should be cautious when making personal revelations on SNS given that certain information could have a negative effect on perceptions of teacher competence.

\section{Design of social networks}

The least numerous category refers to those studies which analyse the design of SNS from a technological perspective. Within this category only one study (Conole \& Culver, 2010) was found which describes the process of designing a social network (Cloudworks) created specifically for use in educational contexts. Although the project described is still under development it highlights the usefulness of this as a tool for discussion, as well as the need to address the design process from a thoughtful approach that allows for flexible and interactive feedback (Conole \& Culver, 2010).

\section{Conclusions}

The review of literature has lead to the conclusion that research on the educational use of SNS has occupied significant place in the international academic agenda over recent years. The abundance of these studies in scientific journals can be interpreted as a consequence of the impact that SNS have had in different settings and dimensions on the lives of people as well as the ability of the academic community to respond quickly to the challenges posed by the emergence of new techno-social tools.

Currently the main body of research on SNS and education is for the most part focused on analysing different variables within higher education. This decision can be understood when taking into account, on the one hand, the policy of creating SNS profiles and, on the other hand, the fact that many researchers use their own contexts to analyse the educational impact that these types of tools could have. This is why widening the focus of attention may be necessary as well as the need to design research directed at finding out how children are using SNS, how their use outside school could be influenced for academic performance or how to integrate SNS in the classroom in these levels of education etc. As some studies have already demonstrated, the companies that own SNS have placed temporary limits on the creation of profiles. This does not mean that, in practice, teenagers are being prevented from using them (Livingstone, Haddon, Görzig \& Òlafsson, 2011). Developing research on pedagogical approaches that teach children how to move around SNS is necessary. 
It has been pointed out, that educational research on SNS is being carried out from different paradigms, although the quantitative paradigm has been the most used over recent years. It should be clarified that the studies analysed, from this perspective, were developed with samples no higher than 70 participants (Brady et al., 2010; Tiryakioglu \& Erzurum, 2011), something which leads to caution with regard to the generalisation of the results. It is also necessary to develop research that runs over a longer period of time. This research should be implemented in different contexts in parallel or successively and from a statistical point of view should use wider more representative samples. The emergence of SNS pose new challenges to the academic community from an epistemological perspective given that these environments are mediated by conditions such as immediacy, the reduced size of published contents or the establishment of relationship networks among users. The academic community needs to develop new strategies for collecting data that respond to these challenges and which allow for the reconstruction of a complex picture of the interaction that occurs in these environments.

The most relevant line of research is one which is directed at analysing different variables related to the possible transformation of SNS into educational tools. In different studies, the academic community has identified some positive and negative aspects as a result of the application of this social tool in formal learning environments. While acknowledging the importance of these types of studies, they clearly demonstrate that research and the educational use of SNS is at an early stage of development. So far, the majority of these studies have been based solely on the concept of a determined technological device (in this case SNS) as a curricular tool. Some of this research has been designed from a traditional approach of studying media in education. This is why some of the texts reviewed are based on a process-product research model which relies on the assumption that the means, by themselves, are capable of improving as much the quality as the quantity of the learning acquired by students, increase in social interaction, motivation etc. (Foulger et al., 2009; Junco et al., 2013; Wang, 2012). Developing research analysing curriculum development processes which use SNS is necessary, this will expand knowledge on key aspects of the integration of this type of media, such as, for example, the preparation of methodological strategies more suited to their use. It would be necessary to review this research from a perspective provided by studies directed at analysing improvement and innovation in education (Fullan, 2005).

Future research into SNS and education should focus on identifying geographical differences in the use of these types of sites, showing the similarities and differences between the practices developed in diverse contexts internationally. Other lines of research should be aimed at analysing how SNS are affecting the policies of integrating ICT in different levels of education when using these tools or the training policies that governments in different countries are adopting in order to train teachers how to integrate these types of resources into their teaching methods.

In the future it will be necessary to design research into media education based on different assumptions which address these devices as educative and as objects of study in their own right (Gutiérrez Martín, 2003). It cannot be ignored that that new media like SNS are cultural industries that build an effective parallel curriculum directed at the construction of identities linked to consumption (Giroux, 2001). New lines of research need to be envisaged, directed at exploring SNS literacy, understood to be a process by which people are provided with the basic tools to manage autonomously and with critical awareness of the information and the culture of the society in which they find themselves immersed (Fueyo, 2008). Proper media education requires not only active participation but also the development of critical understanding (Buckingham, 2005). This becomes even more necessary if it is taken into account that some studies have already highlighted the opportunities that SNS offer to break the boundaries between formal and informal learning (Gao et al., 2012; Manca \& Ranierit, 2013). It would be necessary for educational research to address some lines of research related to the idea of SNS as an object of study. These studies should be directed at researching aspects such as the use of personal data by the companies who own SNS, the models of interaction offered, the underlying concept of privacy in such spaces etc.

The review of literature has also shown that there has been limited analysis by the academic community of the educational use of SNS from a gender perspective. As some studies have shown, this variable plays an important role in the use of some SNS (Aydin, 2012). Within the scope of future research it would be necessary to specifically address the gender variable in order to analyse issues such as; the participation of women in SNS, how students feel when using these devices, what gender images are created in these spaces etc. At the same time research aimed at designing SNS based on an educational approach could incorporate alternative representation, directed, for example, at using iconic images employing textual 
codes compared to visual ones, given that iconic codes possess great demonstrative power, suggesting more explicit meanings, making it more difficult to test different gender identities (Buchmüller \& Joost, 2010).

The limitations of this study are related to decisions about which articles to analyse and the nature of this type of review. The first is related to the exclusion of articles published in scientific conferences and congresses and published in English during the established period of time. It is clear that the inclusion of some of these publications could have provided further insight and would have allowed us to make comparisons between the contributions of researchers to conferences and to scientific journals. The second relates to the nature of meta-research work. The construction of these categories was based on a thorough review of the objects and research subjects identified in the texts. The encoding process is a necessary simplification of the texts analysed, given that some of the references developed lines of research which could be related to several categories. Categorisation was made in relation to the subject that carried greater weight in the study through an analytical process carried out by the research team. The most important aspect of this type of work is the ability to build an overall picture of a given field of research and identify those lines of study which have had a smaller presence and that therefore need to be explored. The number of studies analysed in this paper is higher than other meta-review studies on social networks which range from between 23 and 21 papers and which, for their part, have helped inspire us in the research work presented here (e.g., Aydin 2012; Gao et al., 2012; Manca \& Ranierit, 2013). Despite this it is necessary to understand this research as a partial contribution to a field of knowledge which is still emerging, in constant transformation and which is in the initial stages of methodological development.

\section{References}

Adamic, L. \& Adar, E. (2005). How to search a social network. Social Networks, 27, 187-203.

Ahn, J. (2011). Digital divides and social network sites. Which students participate in social media? Journal of Educational Computing Research, 45(2), 147-163. doi:10.2190/EC.45.2.b

Arnold, N., \& Paulus, T. (2010). Using a social networking site for experiential learning: Appropriating, lurking, modeling and community building. The Internet and Higher Education, 13(4), 188-196. doi:10.1016/j.iheduc.2010.04.002

Aydin, S. (2012). A review of research on Facebook as an educational environment. Educational Technology Research and Development, 60(6), 1093-1106. doi:10.1007/s11423-012-9260-7

Baran, B. (2010). Facebook as a formal instructional environment. British Journal of Educational Technology, 6(41), 46-49. doi:10.1111/j.1467-8535.2010.01115.x

Bearman, M, Smith, C., Carbone, A., Slade, S., Baik, Ch., Hughes-Warrnington, M. \& Neumann, D.(2012). Systematic methodology in higher education. Higher Education Research \& Development, 31(5), 625-640. doi:10.1080/07294360.2012.702735

Bicen, H., \& Cavus, N. (2011). Social network sites usage habits of undergraduate students: Case study of Facebook. Procedia - Social and Behavioral Sciences, 28, 943-947. doi:10.1016/j.sbspro.2011.11.174

Bicen, H., \& Cavus, N. (2012). Twitter usage habits of undergraduate students. Procedia - Social and Behavioral Sciences, 46, 335-339. doi:10.1016/j.sbspro.2012.05.117

Blair, A. (2013). Democratising the learning process: The use of Twitter in the teaching of politics and international relation. Politics, 33(2), 135-145. doi:10.1111/1467-9256.12008

Bosch, T. (2009). Using online social networking for teaching and learning: Facebook use at the University of Cape Town. Communicatio: South African Journal for Communication Theory and Research, 35(2), 185-200. doi:10.1080/02500160903250648

Boyd, D., \& Ellison, N. (2007). Social network sites: Definition, history, and scholarship. Journal of Computer-Mediated Communication, 13(1), 210-230. doi:10.1111/j.1083-6101.2007.00393.x

Brady, K., Holcomb, L., \& Smith, B. (2010). The use of alternative social networking sites in higher educational settings: A case study of the e-Learning benefits of Ning in education. Journal of Interactive Online Learning, 9(2), 151-170.

Buchmüller, S., \& Joost, G. (2010). Las consecuencias del "giro icónico" en las representaciones de género virtuales. ¿La traición de la utopía ciberfeminista? Zafra, R. X0y1. Ensayos sobre género y ciberespacio. (pp. 49-65). Andalucía: Briseño.

Buckingham, D. (2003). Media education: Literacy,learning and contemporary culture. Cambridge: Polity Press. 
Cam, E., \& Isbulan, O. (2012). A new addiction for teacher candidates: Social networks. Turkish Online Journal of Educational Technology, 11(3), 14-19.

Cheung, C., Chiu, P. \& Lee, M. (2011). Online social networks: Why do students use Facebook? Computers in Human Behavior, 27(4), 1337-1343. doi:10.1016/j.chb.2010.07.028

Çoklar, A. N. (2012). Evaluations of students on Facebook as an educational environment. Turkish Online Journal of Qualitative Inquiry, 3(2), 42-53.

Conole, G., \& Culver, J. (2010). The design of Cloudworks: Applying social networking practice to foster the exchange of learning and teaching ideas and designs. Computers \& Education, 54(3), 679-692. doi:10.1016/j.compedu.2009.09.013

Dabner, N. (2012). Breaking ground in the use of social media: A case study of a university earthquake response to inform educational design with Facebook. The Internet and Higher Education. 15(1), 6978. doi:10.1016/j.iheduc.2011.06.001

Davies, J. (2012). Facework on Facebook as a new literacy practice. Computers \& Education, 59(1), 1929. doi:10.1016/j.compedu.2011.11.007

Dilek, G., Karademirb, T., \& Cicek, M. (2011). Problems experienced on educational social networks: Disorientation. Procedia - Social and Behavioral Sciences, 28, 836-841. doi:10.1016/j.sbspro.2011.11.153

Doerr-Stevens, C., Beach, R. \& Boeser, E. (2011). Using online role-play to promote collaborative argument and collective action. English Journal, 100(5), 33-39.

Dunlap. J.C. \& Lowenthal, P.R. (2009). Tweeting the night away: Using Twitter to enhance social presence. Journal of Information Systems Education, 20(2), 129-136.

English, R. \& Duncah-Howell, J. (2008). Facebook@ goes to college: Using social networking tools to support students undertaking teaching practicum. Journal of Online Learning and Teaching, 4(4), 596-601.

Evans, J \& Benefield, P. (2001). Systematic reviews of educational research: Does the medical model fit? British Educational Research Journal, 27(5), 527-541.

Falahah \& Rosmala, D. (2012). Study of social networking usage in higher education environment. Procedia - Social and Behavioral Sciences, 67, 156 -166. doi:10.1016/j.sbspro.2012.11.316

Fardoun, H., Romero, S., Alghazzawi, D. \& Ramírez, J.(2012). Looking for leaders: Reaching the future leaders in education through online social networks. Procedia - Social and Behavioral Sciences, 47, 2036-2043. doi:10.1016/j.sbspro.2012.06.945

Fewkes, A. M., \& McCabe, M. (2012). Facebook: Learning tool or distraction? Journal of Digital Learning in Teacher Education, 28(3), 92-98. doi:10.1080/21532974.2012.10784686

Forkosh-Barucha, A., \& Hershkovitz, A. (2012). A case study of Israeli higher education institutes sharing scholarly information with the community via social networks. The Internet and Higher Education, 15, 58-68. doi:10.1016/j.iheduc.2011.08.003

Foulger, T., Ewbank, A., Kay, A. Popp, S. \& Carter, H. (2009). Moral spaces in MySpace: Preservice teachers' perspectives about ethical issues in social networking. Journal of Research on Technology in Education, 42(1), 1-28. doi:10.1080/15391523.2009.10782539

Fueyo, A. (2008). Alfabetización audiovisual. Una respuesta crítica a la pedagogía cultural de los medios. In R. Aparici (Ed.), Comunicación educativa en la sociedad de la educación (pp. 457-483). Madrid: Universidad Nacional de Educación a Distancia.

Fullan, M. (2005). The meaning of educational change: A quarter of a century of learning. In A. Lieberman (Ed.), The roots of educational change: International handbook of educational change (pp. 205-216). Netherlands: Springer. doi:10.1007/1-4020-4451-8_12

Gao, F., Luo, T., \& Zhang, K. (2012). Tweeting for learning: A critical analysis of research on microblogging in education published in 2008-2011. British Journal of Educational Technology, 43(5), 783-801. doi:10.1111/j.1467-8535.2012.01357.x

Giroux, H. (2001). El ratoncito feroz. Disney o el fin de la inocencia. Madrid: Fundación Germán Sánchez Ruipérez.

Grosseck, G., \& Holotescu, C. (2011). Teacher education in 140 characters - Microblogging implications for continuous education, training, learning and personal development. Procedia - Social and Behavioral Sciences, 11, 160-164. doi:10.1016/j.sbspro.2011.01.053

Gutiérrez Martín, A. (2003). Alfabetización digital. Algo más que ratones y teclas. Barcelona: Gedisa.

Güzin, S., \& Koçak, Y. (2010). Modeling educational usage of Facebook. Computers \& Education, 55(2), 444-453. doi:10.1016/j.compedu.2010.02.008

Hung, H., \& Chi-Yin, S. (2010). Educational use of social networking technology in higher education. Teaching in Higher Education, 15(6), 703-714. 
Irwin, C., Ball, K. \& Desbrow, B.(2012). Students’perceptions of using Facebook as an interactive learning resource at university. Australasian Journal of Educational Technology, 28(7), 1221-1232.

Johnson, R. B., \& Turner, L. A. (2003). Data collection strategies in mixed methods research. In A. Tashakkori \& C. Teddlie (Eds.), Handbook of mixed methods in social and behavioral research (pp. 297-319). Thousand Oaks, CA: Sage.

Jones, N., Backey, H., Fitzgibbon, K. \& Chew, E. (2010). Get out of MySpace! Computers \& Education, 54(3), 776-782.

Junco, R. (2012). The relationship between frequency of Facebook use, participation in Facebook activities, and student engagement. Computers \& Education, 58(1), 162-171.

Junco, R., Elavsky, M., \& Heiberger, G. (2013). Putting Twitter to the test: Assessing outcomes for student collaboration, engagement and success. British Journal of Educational Technology, 44(2), 273-287. doi:10.1111/j.1365-2729.2010.00387.x

Junco, R., Heiberger, G., \& Loken, E. (2011). The effect of Twitter on college student engagement and grades. Journal of Computer Assisted Learning, 27(2), 119-132.

Kamarul, M., Ahmad, N., \& Jafre, M. (2010). Facebook: An online environment for learning of English in institutions of higher education? The Internet and Higher Education, 13(4), 179-187. doi:10.1016/j.iheduc.2010.07.003

Kawka, M., Larkin, K., \& Danaher, P. (2012).Creating Flickr photo-narratives with first-year teacher education students: The possibilities and pitfalls of designing emergent learning tasks. Australian Journal of Teacher Education, 37(11), 1-23. doi:10.14221/ajte.2012v37n11.4

Kim, W., Jeong, O. \& Lee, S. (2010). On social web sites. Information Systems, 35, 215-236.

Knight, J., \& Rochon, R. (2012). Starting online: Exploring the use of a social networking site to facilitate Transition into higher education. The Electronic Journal of e-Learning, 10(3), 259-261.

Lam, L. (2012). An innovative research on the usage of Facebook in the higher education context of Hong Kong. The Electronic Journal of e-Learning, 10(4), 377-386.

Lampe, C., Wohn, D., Vitak, J., Ellison, N., \& Wash, R. (2011). Student use of Facebook for organizing collaborative classroom activities. International Journal of Computer-Supported Collaborative Learning, 6(3), 329-347. doi:10.1007/s11412-011-9115-y

Lim, T., \& Ismail, J. T. (2010). The use of Facebook for online discussions among distance learners. Turkish Online Journal of Distance Education, 11(4), 72-81.

Livingstone, S., Haddon, L., Görzig, A.\& Òlafsson, K. (2011). Risks and safety on the internet: The perspective of European children. London: EU Kids Online. Retrieved from http://eprints.lse.ac.uk/33731/

Lowe, B., \& Laffey, D. (2011). Is Twitter for the birds? Using Twitter to enhance student learning in a marketing course. Journal of Marketing Education, 33(2) 183-192. doi:10.1177/0273475311410851

Madge, C., Meek, J., Wellens, J., \& Hooley, T. (2009). Facebook, social integration and informal learning at university: It is more for socialising and talking to friends about work than for actually doing work. Learning, Media and Technology, 34(2), 141-155. doi:10.1080/17439880902923606

Manca S., \& Ranierit, M. (2013). Is it a tool suitable for learning? A critical review of the literature on Facebook as a technology-enhanced learning environment. Journal of Computer Assisted Learning, 29(6), 1-18. doi:10.1111/jcal.12007

Mazer, J., Murphy, R., \& Simonds, C. J. (2009). The effects of teacher self-disclosure via Facebook on teacher credibility. Learning, Media and Technology, 34(2), 175-183. doi:10.1080/17439880902923655

McCarthy, J. (2012). International design collaboration and mentoring for tertiary students through Facebook. Australasian Journal of Educational Technology, 28(5), 755-775.

McCarthy, J., (2013). Learning in Facebook: First year tertiary student reflections from 2008 to 2011. Australasian Journal of Educational Technology, 29(3), 337-356.

Nielsen (2012). State of the media. The social media report 2012. Retrieved from http://www.nielsen.com/us/en/reports/2012/state-of-the-media-the-social-media-report-2012.html

Ólafsson, K., Livingstone, S., \& Haddon, L. (2013). Children's use of online technologies in Europe. A review of the european evidence base. London: EU Kids Online. http://eprints.lse.ac.uk/50228/

Osborn, D. S. \& LoFrisco, B. M. (2012). How do career centers use social networking sites? The Career Development Quarterly, 60(3), 263-272. doi:10.1002/j.2161-0045.2012.00022.x

Park, S., Cha, S., Lim, K., \& Jung, S. (2013). The relationship between university student learning outcomes and participation in SNS, social acceptance and attitude towards school life. British Journal of Educational Technology, 44(1), 1-15. 
Pempek, T., Yermolayeva, Y., \& Calvert, S. (2009). College students' social networking experiences on Facebook. Journal of Applied Developmental Psychology, 30(3), 227-238. doi:10.1016/j.appdev.2008.12.010

Pimmer, C., Linxen, S., \& Gröhbiel, U. (2012). Facebook as a learning tool? A case study on the appropriation of social network sites from mobile phones in developing countries. British Journal of Educational Technology, 43(5), 726-738. doi:10.1111/j.1467-8535.2012.01351.x

Ranieri. M., Manca, S., \& Fini, A. (2012). Why (and how) do teachers engage in social networks? An exploratory study of professional use of Facebook and its implications for lifelong learning. British Journal of Educational Technology, 43(5), 754-769. doi:10.1111/j.1467-8535.2012.01356.x

Rambe, P. (2012). Critical discourse analysis of collaborative engagement in Facebook postings. Australasian Journal of Educational Technology, 28(2), 295-314.

Rambe, P. (2013). Converged social media: Identity management and engagement on Facebook Mobile and blogs. Australasian Journal of Educational Technology, 29(3), 315-336.

Reich, J., Levinson, M., \& Johnston, W. (2011). Using online social networks to foster preservice teachers' membership in a networked community of praxis. Contemporary Issues in Technology and Teacher Education, 11(4), 382-397.

Rinaldo, R., Tapp, S., \& Laverie, D. (2011). Learning by tweeting: Using Twitter as a pedagogical tool. Journal of Marketing Education, 33(2), 193-203. doi:10.1177/0273475311410852

Roblyer, M. D., McDaniel, M., Webb, M., Herman, J., \& Witty, J. V. (2010). Findings on Facebook in higher education: A comparison of college faculty and student uses and perceptions of social networking sites. The Internet and Higher Education, 13(3), 134-140. doi:10.1016/j.iheduc.2010.03.002

Schroeder, J., \& Greenbowe, T. (2009). The chemistry of Facebook: Using social networking to create an online community for organic chemistry. Innovate: Journal of Online Education, 5(4), 1-10.

Selwyn, N. (2009). Faceworking: Exploring students' education-related use of Facebook. Learning, Media and Technology, 34(2), 157-174. doi:10.1080/17439880902923622

Sezen, G. (2012). Social networking in physical education: Undergraduate students’ views on Ning. Turkish Online Journal of Distance Education, 13(2), 277-290.

Staines, Z., \& Lauchs, M. (2013). Students' engagement with Facebook in a university undergraduate policing unit. Australasian Journal of Educational Technology, 29(6), 792-805.

Thomas, G., \& Pring, R. (2004). Evidence-based practice in education. Maidenhead: Open University Press.

Tiryakioglu, F., \& Erzurum, F. (2011). Use of social networks as an education tool. Contemporary Educational Technology, 2(2), 135-150.

Veletsianos, G., \& Kimmons, R. (2013). Scholars and faculty members' live experiences in online social networks. The Internet and Higher Education, 16, 43-50. doi:10.1016/j.iheduc.2012.01.004

Wang, C.-M. (2012). Using Facebook for cross-cultural collaboration: The experience of students from Taiwan. Educational Media International, 49(1), 63-76. doi:10.1080/09523987.2012.662625

Wang, Q., Woo, H., Quek, C., Yang, Y., \& Liu, M. (2011). Using the Facebook group as learning management system: An exploratory study. British Journal of Educational Technology, 43(3) 428438. doi:10.1111/j.1467-8535.2011.01195.x

Yan Yu, A., Wen, S., Vogel, D., \& Chi-Wai, R. (2010). Can learning be virtually boosted? An investigation of online social networking impacts. Computers \& Education, 55(4), 1494-1503. doi:10.1016/j.compedu.2010.06.015

Corresponding author: Carlos Rodríguez-Hoyos, rodriguezhc@unican.es

Australasian Journal of Educational Technology @ 2015.

Please cite as: Rodríguez-Hoyos, C., Haya, I., Fernández-Díaz, E. (2015). Research on SNS and education: The state of the art and its challenges. Australasian Journal of Educational Technology, 31(1), 100-111. 